\title{
Onvoldoende gebruik in de huisartsenopleiding van de lijst met eindtermen van medische problemen
}

\author{
J. Michels, A. Derese, R. Remmen, D. Leroy
}

\section{Samenvatting}

Inleiding: Om het praktische deel van de opleiding tot huisarts in Vlaanderen beter te structureren werd door het Interuniversitair Centrum voor Huisartsenopleiding een lijst met eindtermen van medische problemen in de huisartsopleiding opgesteld.

Methode: Met een schriftelijke enquête wordt in deze studie nagegaan wat de onderwijskundige waarde is van deze lijst.

Resultaten: Het onderzoek toont aan dat de lijst als opleidingsinstrument niet optimaal functioneert.

Discussie: Om het gebruik van de lijst te verbeteren wordt een aantal aanbevelingen gedaan: het doel nauwkeuriger toelichten, de gebruiksvriendelijkheid verhogen, er meer bekendheid aan geven, systematisch gebruiken in de opleidingsgesprekken en de lijst op een meer expliciete manier met het eindexamen verbinden. (Michels J, Derese A, Remmen $R$, Leroy $D$. Onvoldoende gebruik in de huisartsopleiding van de lijst met eindtermen van medische problemen. Tijdschrift voor Medisch Onderwijs 2001;20(2):70-75.)

\section{Inleiding}

In Vlaanderen kiezen aanstaande huisartsen in het zevende jaar van de opleiding de oriëntatie huisartsenopleiding. Deze oriëntatie omvat theoretische lessen, trainingen (onder andere in communicatievaardigheden en consultvoering) en enkele stages. De oriëntatie wordt gegeven aan de vier Vlaamse Universiteiten. Vervolgens lopen de studenten een stage van twee jaar in erkende huisartspraktijken en ziekenhuisdiensten. Deze huisartsen-in-beroepsopleiding (HIBO's) volgen ook seminaries: tweewekelijkse bijeenkomsten in vaste groepen van ongeveer vijftien HIBO's die in dezelfde regio werken. Deze seminariegroepen worden geleid door coördinatoren (ervaren huisartsen). Tijdens die seminaries worden eigen ervaringen en vragen van de HIBO's besproken. De stageperiode wordt afgesloten met een examen. De HIBO die voor dit examen slaagt, kan zich vestigen als huisarts.
HIBO's en hun praktijkopleiders beschikken over een lijst van zorgvuldig geformuleerde eindtermen. ${ }^{1}$ Hierin wordt een volledig overzicht gegeven van de kennis, vaardigheden en attitudes die een HIBO tijdens de opleiding tot huisarts moet leren. Zo bevat de lijst eindtermen op het vlak van klinische en technische vaardigheden, consultvoeringsvaardigheden, administratieve taken en professioneel gedrag. Er is ook een overzicht van 240 medische problemen in de huisartsgeneeskunde opgesteld. Tabel 1 toont hoe de medische problemen in de lijst worden gepresenteerd samen met hun frequentie per duizend arts-patiëntcontacten in de praktijk van beginnende Vlaamse huisartsen en de belangrijkste aandachtspunten waarmee rekening gehouden dient te worden. De lijst kwam tot stand in nauwe samenspraak met de Vlaamse huisartsencentra, HIBO's en praktijkopleiders en werd aangevuld met gegevens uit de richtlijnen van 
Tabel 1. Voorbeeld uit de lijst van medische problemen.

\section{Tractus Digestivus}

\begin{tabular}{|c|c|c|c|}
\hline$\overline{\text { ICPC }^{*}}$ & Prevalentie & Medisch probleem & Aandachtspunten huisartsgeneeskundig beleid \\
\hline \multirow[t]{3}{*}{ D73 } & $25 \%$ & Virale gastro-enteritis & - Aanpak bij kinderen en volwassenen \\
\hline & & & - Voorkomen van besmetting \\
\hline & & & - Voorlichting i.v.m. dieet \\
\hline \multirow[t]{5}{*}{ D93 } & $11 \%$ & Spastisch colon & - Diagnose door aanwezigheid van aantal symptomen \\
\hline & & & en afwezigheid van organische pathologie \\
\hline & & & - GVO: etiologie en therapie \\
\hline & & & - Dieet adviezen \\
\hline & & & - Meersporenbeleid/beperken technisch beleid \\
\hline \multirow[t]{5}{*}{ D12 } & $4 \%$ & Obstipatie & - Obstipatie bij bejaarden \\
\hline & & & - Preventie obstipatie \\
\hline & & & - Obstipatie als gevolg van medicatie \\
\hline & & & - Beleid bij faecalomen \\
\hline & & & - Samenwerking met verpleegkundige (lavement) \\
\hline
\end{tabular}

${ }^{*}$ Code uit de International Classification of Primary Care

de Wetenschappelijke Vereniging van Vlaamse Huisartsen, de standaarden van het Nederlands Huisartsen Genootschap (NHG) en andere bronnen. ${ }^{2-6}$

De lijst maakt deel uit van de Handleiding die de HIBO bij het begin van de opleiding ter hand krijgt gesteld. In de inleiding wordt de lijst aanbevolen als praktisch hulpmiddel om het eigen leerproces te bevorderen. De praktijkopleider, die eveneens een exemplaar van de lijst krijgt toegestuurd, kan aan de hand van de lijst lacunes vaststellen en op basis hiervan de leeragenda van de HIBO bijstellen.

In 1998 werd onderzocht wat de onderwijskundige waarde is van de lijst met medische problemen in de huisartsgeneeskunde. De onderzoeksvragen betroffen het gebruik van de lijst door HIBO's en praktijkopleiders en de knelpunten die zij daarbij ervaren.

\section{Methode}

Om een indruk te krijgen van de ervaringen van HIBO's en praktijkopleiders met de lijst werd aan HIBO's en praktijkopleiders een enquête voorgelegd. Naast vijf vragen die bedoeld waren voor zowel HIBO's als praktijkopleiders, waren er twee vragen die voor HIBO's en praktijkopleiders verschillend waren. Bij elke vraag was er gelegenheid om commentaar te geven. De enquête werden per post voorgelegd aan de HIBO's ( $n=247)$ die in september 1998 hun tweede opleidingsjaar beëindigden en hun praktijkopleiders $(n=247)$. De enquête was anoniem. De kwantitatieve gegevens werden verwerkt met Excel. De kwalitatieve gegevens werden eerst letterlijk overgenomen en nadien gecategoriseerd. De vragen die gesteld werden, waren de volgende:

1. Hebt u gebruikgemaakt van de lijst als werkinstrument?

2. Wat was de concrete aanleiding of situatie om de lijst te gebruiken?

3. Is de lijst geslaagd als overzicht van aandoeningen in de huisartspraktijk?

4. Is de lijst geslaagd als aanduiding van de frequentie van deze aandoeningen? 
5. Is de lijst geslaagd als aanduiding van de belangrijkste aandachtspunten bij deze aandoeningen?

Aparte vragen voor HIBO's

6. Hebt u de lijst (gedeeltelijk) doorgenomen met uw opleiders?

7. Zou u, als u de lijst niet had gehad, even ver zijn in uw evolutie als huisarts?

Aparte vragen voor praktijkopleiders

6. Hebt u de lijst (gedeeltelijk) doorgenomen samen met uw HIBO?

7. Heeft de lijst u geholpen bij uw opleidingstaak?

\section{Resultaten}

Honderd HIBO's (41\%) en 106 praktijkopleiders $(43 \%)$ retourneerden de enquête. Van de responderende HIBO's heeft 21\% de lijst nooit gebruikt, $46 \%$ heeft de lijst één keer gebruikt en 33\% heeft de lijst meerdere keren gebruikt. Van de praktijkopleiders die reageerden, had 22\% de lijst nooit gebruikt, 34\% had de lijst één keer gebruikt en $44 \%$ had de lijst meerdere keren gebruikt. De resultaten van de verwerking van de antwoorden van de HIBO's en de praktijkopleiders die de lijst vaker dan eenmaal hebben gebruikt, zijn weergegeven in tabel 2. De meningen over de lijst en het gebruik ervan van de HIBO's en de praktijkopleiders worden in het onderstaande afzonderlijk gepresenteerd.

\section{Meningen HIBO's}

Achtenzeventig procent van de HIBO's vond de lijst een hulp bij de opleiding tot huisarts. Er werden 38 aanleidingen geformuleerd om de lijst te gebruiken. Vaak was een evaluatie van zichzelf de aanleiding. Soms was het nieuwsgierigheid, de

Tabel 2. Overzicht van de antwoorden van de HIBO's $(n=33)$ en praktijkopleiders (PO's) ( $n=44)$ die de lijst meer dan 1 keer gebruikt hebben.

\begin{tabular}{lllll}
\multicolumn{2}{c}{ HIBO (\%) } & & \multicolumn{2}{c}{ PO (\%) } \\
\cline { 4 - 5 } & nee & ja deels & nee & ja deels
\end{tabular}

Lijst geslaagd als:

- overzicht van huisartsgeneeskundige aandoeningen $\quad \begin{array}{llllll}0 & 73 & 27 & 2 & 63 & 35\end{array}$

- weergave van de frequentie van de aandoeningen $\quad \begin{array}{lllllll}0 & 41 & 59 & 7 & 44 & 49\end{array}$

- aanduiding van de belangrijkste aandachtspunten $\quad \begin{array}{llllll}3 & 49 & 48 & 7 & 59 & 34\end{array}$

per aandoening

Lijst doorgenomen met praktijkopleiders

2971

Lijst doorgenomen met stagemeester/coördinator $\quad 50 \quad 50$

Lijst doorgenomen met HIBO

$\begin{array}{lll}0 & 100\end{array}$

\begin{tabular}{|c|c|c|c|}
\hline \multicolumn{2}{|c|}{ HIBO (\%) } & \multicolumn{2}{|c|}{ PO (\%) } \\
\hline $\begin{array}{l}\text { hielp } \\
\text { verder/ } \\
\text { veel }\end{array}$ & $\begin{array}{l}\text { overbodig } \\
\text { weinig } \\
\text { hulp }\end{array}$ & $\begin{array}{l}\text { hielp } \\
\text { verder/ } \\
\text { veel }\end{array}$ & $\begin{array}{l}\text { overbodig } \\
\text { weinig } \\
\text { hulp }\end{array}$ \\
\hline
\end{tabular}

Lijst als hulp bij ontwikkeling als huisarts

78

22

Lijst als hulp bij opleidingstaak

49

51 
voorbereiding voor het examen, of om in de ziekenhuisstage toch te weten welke medische problemen voor de huisartspraktijk belangrijk zijn. De HIBO's zijn enthousiast over de lijst als overzicht van aandoeningen (ja 73\%; gedeeltelijk 27\%); iets minder enthousiast zijn zij over de lijst als weergave van de frequentie (ja 41\%; gedeeltelijk 59\%) en als aanduiding van aandachtspunten (ja 49\%; gedeeltelijk $48 \%$ ). Degenen die de lijst nooit gebruikt hadden, gaven als redenen: de lijst nooit ontvangen, geen tijd, onpraktisch document, papierberg. Sommige respondenten betwijfelden of de opgegeven prevalentie van de medische problemen wel met de realiteit overeenkwam. HIBO's die de lijst niet samen met de praktijkopleiders doorgenomen hadden (29\%), schreven dit soms toe aan een gebrek aan interesse van de opleider. De helft van de HIBO's had de lijst doorgenomen met de stagemeester/coördinator. Een enkele keer werd de lijst als een verregaande betutteling van het leerproces door het Interuniversitair Centrum voor Huisartsenopleiding (ICHO) ervaren. Vaak vond men het beter voort te gaan op wat zich aanbood in de praktijk dan zich te baseren op lijsten.

\section{Meningen van de opleiders}

Negenenveertig procent van de praktijkopleiders die de lijst meer dan één keer gebruikt hebben, beweert dat de lijst hulp bood bij hun opleidingstaak. Als overzicht van medische problemen voldeed de lijst bij $63 \%$ en bij $35 \%$ voldeed de lijst gedeeltelijk. De mening over de lijst als weergave van de frequentie van aandoeningen (ja 44\%, gedeeltelijk 49\%) en over de aanduiding van de belangrijkste aandachtspunten (ja 59\%; gedeeltelijk 34\%) was minder gunstig. Ook praktijkopleiders twijfelden aan de opgegeven prevalentie in de huisartspraktijk. Onbekendheid, tijdgebrek en te hoge moeilijkheidsgraad werden genoemd als redenen om de lijst niet te gebruiken. Aanleidingen om de lijst wel te gebruiken waren een evaluatiemoment met de HIBO, het toetsen van de eigen kennis als opleider en de evaluatie van de geboden opleiding aan de HIBO. Tijdgebrek was de belangrijkste reden om de lijst niet met de HIBO door te nemen. Andere redenen om de lijst niet te gebruiken, waren dat men liever zelfmeegemaakte casussen besprak en literatuur raadpleegde. Ook werd gemeld dat de HIBO het bespreken van de lijst wel eens ontweek. Positieve uitspraken kwamen ook voor: "als ziekenhuispraktijkopleider kende ik de lijst niet, maar in de toekomst zal ik ze zeker gebruiken", "de lijst gaf me de kans na te gaan of de HIBO voldoende aspecten van de huisartsgeneeskunde tegenkwam". Respondenten die weinig hulp ondervonden van de lijst merkten op dat ze te uitgebreid was, dat per medisch probleem toch extra literatuurbronnen nodig zijn en dat de HIBO ook zonder lijst vroeg of laat wel met de vermelde medische problemen in aanraking zou komen. Sommige respondenten vonden de lijst té uitgebreid, anderen vroegen juist om meer aandachtspunten voor het huisartsgeneeskundig beleid. De classificatie volgens de International Classification of Primary Care riep soms vragen op. ${ }^{7}$ Er werd aangegeven dat niet alles wat zich in een huisartsconsultatie afspeelt op papier gezet kan worden. Alle praktijkopleiders hebben de lijst met hun HIBO doorgenomen.

\section{Bespreking en aanbevelingen}

De studie heeft als beperking dat er slechts een geringe respons was. Een belangrijke conclusie is dat de lijst voor de respondenten momenteel niet optimaal functioneert als opleidingsinstrument. Onze belangrijkste verwachting, namelijk 
dat de lijst regelmatig wordt gebruikt om de eindtermen van de huisartsenopleiding te bereiken, blijkt niet juist. Een groot gedeelte van de praktijkopleiders gaf aan dat de lijst hen weinig hielp bij hun opleidingstaak. Veel meer praktijkopleiders dan HIBO's beweren de lijst gezamenlijk doorgenomen te hebben, maar hier is wellicht sprake van positieve selectie of sociale wenselijkheid. In de vele gevallen waar de lijst niet gezamenlijk doorgenomen werd, rijst de vraag wat er dan wél gebeurt tijdens bijvoorbeeld het intakegesprek van de HIBO's.

De lijst wordt blijkbaar vooral als een zelfevaluatie-instrument gezien. De waarde hiervan is echter beperkt omdat zelfbeoordelingen op het gebied van medische kennis geen krachtige voorspellers van competentie zijn. ${ }^{8}$ Dat sommige praktijkopleiders de lijst ook gebruiken om voor zichzelf eigen leerdoelen op te stellen is een onverwachte maar interessante toepassing van de lijst. HIBO's zien de lijst soms als voorbereiding op het examen. De lijst biedt blijkbaar een houvast voor de eigen opleiding voor de HIBO's en praktijkopleiders.

De knelpunten kunnen als volgt samengevat worden. Een deel van de respondenten vindt de lijst een saai en onhandig instrument dat voor sommigen te beperkt en voor anderen dan weer te uitgebreid is. Voor sommige opleiders brengt de lijst niets nieuws. Het ICHO krijgt hierbij het verwijt een papierberg te genereren. De juistheid van de prevalentie van de problemen wordt door een aantal respondenten betwijfeld. De lijst in de dagelijkse onderwijspraktijk gebruiken is blijkbaar niet gemakkelijk. De lijst blijkt niet bij iedereen even goed bekend te zijn en als men de lijst toch kent, vindt men weinig tijd om ze te gebruiken.

Het aanbieden van opleidingsmogelijkheden en -instrumenten is geen garantie voor het behalen van de eindtermen. Er is systematische aandacht voor het gebruik van dit opleidingsinstrument nodig. Wanneer in het onderwijsproces en bij het eindexamen de lijst met eindtermen wordt gebruikt, zal dit het ontstaan van een 'krachtige' leeromgeving bevorderen. ${ }^{9}$ Om de waarde van de lijst als opleidingsinstrument te verbeteren, hebben wij de volgende suggesties:

- Doelstellingen voor HIBO en praktijkopleider moeten duidelijker geformuleerd worden en de lay-out moet op sommige punten verbeterd worden.

- HIBO's, praktijkopleiders en coördinatoren moet geleerd worden te werken met de lijst door aan te geven dat zelfbeoordeling een van de mogelijkheden is om de opleiding te structureren.

- De lijst dient als vast punt tijdens het intakegesprek met de coördinator of tijdens stages in de opleidingspraktijken gebruikt te worden. Ook in de seminariegroepen kan de lijst geraadpleegd worden.

- De lijst dient gebruikt te worden in de evaluatie van studenten. De studenten moet duidelijk gemaakt worden dat toetsen tijdens het eindexamen deels op deze lijst gebaseerd zijn.

- Daarnaast dient ervoor gezorgd te worden dat meer eindtermen van de opleiding tot huisarts effectief worden aangeleerd tijdens de opleiding. ${ }^{10}$

\section{Literatuur}

1. Toetslijst voor huisartsen-in-beroepsopleiding en stagemeesters. Interuniversitair Centrum voor Huisartsenopleiding. Leuven; 1997.

2. Derese A. Huisarts in beroepsopleiding, een hypothesevormend onderzoek [proefschrift]. Gent: Vakgroep Huisartsgeneeskunde en Eerstelijnsgezondheidszorg. Rijksuniversiteit Gent; 1992.

3. Derese A. Eindtermen van de beroepsopleiding tot huisarts. Intern document. Interuniversitair Centrum voor Huisartsenopleiding. Leuven; 1996.

4. Deceulaer C, Boogaerts E, Charlier M, Grouwels D, Verdonck P. Basistakenpakket voor de huisart- 
senpraktijk. Antwerpen: Wetenschappelijke Vereniging van Vlaamse Huisartsen; 1994.

5. Nottingham Vocational Training Scheme for GP. Education and formative assessment package for general practice. Sine die.

6. Metz JCM, Pels Rijcken-Van Erp Taalman Kip EH, Brand van den-Valkenburg BWM. Raamplan 1994 artsopleiding. Eindtermen van de artsopleiding. Nijmegen: Universitair Publikatiebureau, Katholieke Universiteit Nijmegen; 1994.

7. Boersma J, Gebel RS. ICPC: international classification of primary care: short titles (vertaald in het Nederlands) en Nederlandse subtitels, onder redactie van: Boersma JJ, Gebel RS, Lamberts H. Utrecht: Nederlands Huisartsen Genootschap; 1993.

8. Tracey JM, Arroll B, Richmind DE, Barham P. The validity of general practioners' self assessment of knowledge: cross sectional study. British Medical Journal 1997;315:1426-8.

9. Simons PRJ. Een leerpsychologische analyse van medisch onderwijs. In: Spaai GWG, Verweij AMJJ, Remmen R, Dolmans DHJM, Denekens JPM, Smal JA, et al, redactie. Gezond Onderwijs - 8 . Houten/ Diegem: Bohn Stafleu Van Loghum; 1998. p. 3-13.
10. Remmen R. An evaluation of clinical skills training at the medical school of the University of Antwerp [proefschrift]. Antwerpen: Universiteit van Antwerpen; 1999.

De auteurs:

J. Michels is huisarts in Tielt, medewerker van de stafgroep curriculum van het Interuniversitair Centrum voor Huisartsenopleiding (ICHO) en verbonden aan het huisartsencentrum van de Vrije Universiteit Brussel.

Prof. dr. A. Derese is docent huisartsgeneeskunde bij de Vakgroep Huisartsgeneeskunde en Eerstelijnsgezondheidszorg RUG en bij het Interuniversitair Centrum voor Huisartsenopleiding (ICHO) en onderwijsdirecteur van de Faculteit Geneeskunde en Gezondheidswetenschappen RUG. Hij werkt als huisarts in het Wijkgezondheidscentrum Botermarkt te Gent. Dr. R. Remmen is huisarts in Baarle Hertog en medewerker aan het centrum voor Huisartsgeneeskunde van de Universiteit van Antwerpen.

$D$. R. Leroy is directeur van het het Interuniversitair Centrum voor Huisartsenopleiding (ICHO).

Correspondentieadres:

Jan Michels, huisarts, Kortrijkstraat 95, 8700 Tielt, België, tel: 051-403255, e-mail: lok.1395@hnbe.com.

\section{Summary}

Introduction: Quality assurance is a high priority in vocational training for general practitioners in Flanders. To improve the training programme, a checklist of primary care problems was designed to be used by both trainers and trainees to monitor the students' progress and detect deficiencies that need addressing. The list is handed out to trainees and trainers at the start of the vocational training programme.

Method: In order to evaluate the effects of the list, a questionnaire was mailed to 247 trainers and trainees.

Results: The response shows that the checklist was not optimally used.

Discussion: In order to promote more effective use of the checklist of medical problems it is recommended that the purpose of the list should be explained more clearly, the list should be made more user friendly, be publicised more extensively, be used systematically in educational encounters of trainers and trainees, and be more explicitly linked to the final examination. (Michels $J$, Derese A, Remmen $R$, Leroy D. A checklist of medical problems for general practice training is not used successfully. Dutch Journal of Medical Education 2001;20(2):70-75.) 